\title{
Does Social Network Improve Social Communication?
}

\author{
Qahraman Abdullah Hameed \\ Department of Kurdish Language, College of Art, University of Dohuk, Iraq
}

Copyright $(2015$ by authors, all rights reserved. Authors agree that this article remains permanently open access under the terms of the Creative Commons Attribution License 4.0 International License

\begin{abstract}
The rationale of this paper is to suggest that social communication has a positive influence on social life in terms of family, education and healthcare. In addition, the social network has become a basic need for many people in the world. The reason for this is that people contact one another as part of their social lives through the social network, while others carry on their businesses within the social network.
\end{abstract}

\section{Keywords Social Network, Social Communication}

\section{Introduction}

Nowadays, the practice of forming relationships through social media enables people to understand one another by sharing their feelings, thoughts and ideas. The Internet has become a significant tool of social communication. Social media have offered many people a second life. Students acquire information from it, families use it to connect with their relatives, and doctors use it to promote good general healthy living. The purpose of this essay is to propose that social communication has a positive impact on social life in terms of family, relationships, education and healthcare. This essay is divided into four sections. In the first section, the positive points of social communication for those who use it to make social contacts, form friendships and stay in touch with families are discussed. The second section analyses the positive points of social communication in many types of relationship. The third analyses its advantages for education and how it can be used by students. The fourth section analyses the positive points of electronic media networks in terms of healthcare benefits.

\section{Materials and Method}

The researcher has focused on the good aspects of people's use of the social network throughout this research. This is because it enables people to enhance their social lives and makes their real lives easier. Furthermore, secondary data have been used to find new results on this topic. These data have been analysed in detail as part of the qualitative methodological philosophy to find facts.

\section{Result}

It is found that the social network has many good effects on people's social lives; people can contact their doctors, and students can contact teachers. Thus, communication becomes very easy and fast. However, the social network has some drawbacks for people's social lives. For example, Facebook and Google encourage students to talk at length with their friends, resulting in them failing to pay attention to their studies. Therefore, it can be said that the social network is very important in enabling people to communicate with one another; however, there are some drawbacks to using this technology, and people should be aware of the risks of using it and protect themselves from its negative aspects.

Advantages and disadvantages of social network:
\begin{tabular}{|c|c|}
\hline Advantages & Disadvantages \\
\hline $\begin{array}{c}\text { Good effects on people's social } \\
\text { lives }\end{array}$ & $\begin{array}{c}\text { students busy talking with their } \\
\text { friends }\end{array}$ \\
\hline Patients can contact their doctors & $\begin{array}{c}\text { there is a risk of hackers hacking } \\
\text { people's profiles }\end{array}$ \\
\hline Students can contact teachers & $\begin{array}{c}\text { social network is used to } \\
\text { encourage use of alcohol }\end{array}$ \\
\hline
\end{tabular}

\section{Discussions}

The social network sites offer a large group of people the chance to communicate. According to Boyd and Ellison (2007:2), the social networks are "web-based services that allow individuals to (1) construct a public or semi-public profile within a bounded system, (2) articulate a list of other users with whom they share a connection, and (3) view and traverse their list of connections and those made by others within the system". This means there is a system that allows people to connect with one another and exchange ideas and feelings. Electronic media networks are considered to have many advantages for those who use them for social contact. According to Wellman \& Haythornthwaite (2002), social communication may be used by two thirds of people as it is 
useful for communication with family and friends. For instance, this tool can be used by overseas students as a basic way of staying in touch with their families and friends. This means that social networks can act as a bridge between people from different countries or different places, especially overseas students. In addition, they can be used by the majority of people who simply want to chat with other people. Hence, this phenomenon has grown rapidly (Horton, 2001). As a result, people are seeking all available ways to chat with one another. However, no serious research has yet examined whether the use of social networks has been successful in improving social communication.

According to Philips and Young (2009), some people believe that electronic media networks are important to their lives, while others think they are not. Some people believe they can easily do many things on the social network while other people argue that they can do them without the social network. For example, students do not need the social network to know everything about their studies when they chat with their tutors, while some students regard it as very important for this aim. Furthermore, friends convey messages to other friends; children who live abroad employ the internet services on their mobiles to talk to their close relatives (Wellman \& Haythornthwaite, 2002). In such cases, the social network is very important for enabling students to contact their families and avoid having to travel to their home countries to see their parents. In addition, many people consider it important because it allows them to chat online with relatives in different places in the world, such as parents in Bulgaria, cousins in Spain, and friends in London, the USA and Canada, as the world has become like a village (Bakardjieva, 2005). However, many countries are opposed to this kind of communication and treat it as a threat. In other words, these countries try to control this service, such as in China and Iran (Horton, 2001). As a result, families use social networks as a tool to connect with their members in different places.

However, there is risk of hackers hacking into people's profiles and viewing their private lives on Facebook. According to Debatin et al., (2009), web services enable many people to spy on other people's lifestyles negatively. For example, in many countries people's life secrets have been hacked by hackers; they have stolen their photos or videos, affecting their private lives and putting their social lives in danger. Hence, people should be aware of this problem and avoid uploading many private photos and details on Facebook or other social web services to avoid the risk of hacking. Furthermore, the social network occasionally breaks relationships between people. According to Lin (1999), some men check their wives' mobiles to view their private profiles; this causes problems between them, leading to divorce. Thus, the social network may damage families and relationships. However, not enough has been done to safeguard social life secrets. In other words, governments must work more seriously to maintain people's privacy.

Many people believe that relationships are sustained by the electronic media networks because it is easy to stay in touch with people from different countries. For that reason, some people think that new relationships are formed by people seeking to understand each other's culture and share their feelings and thoughts. There has recently been an increasing focus on contact via electronic media networks (Duck, 2007). As a result, people can share many experiences through web services. Although the social media have been transformed into a huge society of challenging communicators, people's lives are controlled by the electronic media networks as they seek to exchange information about many things such as sport, health, travel and news; thus, they spend most of their time on the social media (Wellman \& Haythornthwaite, 2002). Therefore, people cannot ignore the role of the social network in social and health matters.

These days, it may be easy for people to access every form of information in every part of the globe. For instance, it clearly enables people to join groups and share photos and videos (Brown, 2009). Thus, it is easy to chat with people in groups and send one another videos about society, science, health, politics and culture. Moreover, the social network can be used by politicians in their election campaigns; they may post their families' photos and videos on the social network to boost their image. This is a good way of making others think that they are open-minded people who have good relationships with their audience. For instance, Barack Obama engaged with the most high-profile social networks such as MySpace, Twitter and Facebook (Brown, 2009). However, in Canada people have felt cheated by politicians. For example, the minister of health cheated people by promising but failing to work for better health services (Kondro, 2007). Thus, the social network plays a vital role in politics by increasing the number of people interested in electing specific politicians. However, many people show alcohol on social media to encourage others to give information as advertisements for some types of alcohol. In their analysis, Moreno et al. (2010) stated that many males showed information about alcohol in their profiles on social media. In the same way, some information about alcohol on social media might be used by peers to encourage the use of alcohol. Nevertheless, some of them use social media to provide information about the problems caused by drinking alcohol. Hence, the social network plays a negative role by drawing people's attention to bad things. Accordingly, people all over the world use social networks as a tool to connect with others. Besides, it may be important to move on to a new point regarding the social network's advantages. However, there are no clear statistics on how the social network has damaged young people by causing them to become addicted to alcohol.

There appears to be another benefit of social networking websites: people form groups in many countries while abroad, particularly students. Phillips and Young $(2009,95)$ explain: "the internet is about mass audiences and small groups working, communication and playing across many cultures that are at the same time both local and global." 
Thus, it could be said that many groups of students can swap information about their subjects at numerous universities around the world. For example, the Internet can be used to exchange information with other students around the world at Harvard University (Brown, 2009). Furthermore, it is thought some students use social media as a tool to support their learning. For example, they may use Facebook to speak with their peers during their courses. According to Stefan \& Naghmeh (2012), some use it to exchange their experiences in face-to-face meetings and some use it to manage their group work. For example, in many developed countries university students use this facility. Besides, the social network is the most perfect and the fastest way to share knowledge with each other from different parts of the world. This is because knowledge and information can be shared between several persons in different ways during their daily lives (Irene, 2012). According to Veletsianos and Navarrete (2012: 1), "Social networking sites (SNSs) have the potential to facilitate interaction, communication, and collaboration... online social networks enable learners and instructors to present themselves socially in an online environment and connect with one another while enabling individuals to engage in recurring meaningful experiences with others". This means there is an excellent opportunity to distribute particular experiences with other people. As a result, students and teachers can use social networks to swap their experiences with others. However, there is no guarantee that publishers of ideas will be able to protect their rights from thieves. According to Fornahl, Zellner and Audretsch (2005), other people have opportunities to steal publishers' ideas online. Thus, there is a risk of information being stolen by other people.

Moreover, a survey of many teachers and librarians has established that social networks can be helpful for the exchange of ideas and information. "As reported in School Principals...1,200 principals, teachers and librarians found that most agreed that social networking sites can help educators share information and resources, create professional learning communities and improve school wide communications with students and staff." (Bumgardner and Knestis, 2011) Thus, students use social networks as a tool to connect with their colleagues. Besides, it might be important to move on to a new point about social network advantages.

However, some people have noted that the social network has some disadvantages for people. According to Borbone (2009), it distracts students from their work and they become lazy. For example, Facebook and Google encourage students to chat with their friends and ignore their studies. Hence, many students may fail in their studies because they are too busy with social web services.

On the other hand, another advantage of social networking websites is that they can be used by patients and doctors. According to Sharp (2010), this type of community is growing in wealthy environments especially in condition-specific communities. This means that the social network may be useful in many other serious fields such as healthcare. In addition, a survey has found that the social network helps people to learn more about diseases and protect themselves from the factors that cause diseases. The survey states that "social media can be used as an effective tool to prevent disease and promote general health" (Valente and, Cooper, 2010). Furthermore, the delivery of health promotion interventions is offered by online social networking sites because they have the potential to reach a large population comparatively cheaply (Gold, 2012). Thus, social networking sites such as Facebook and MySpace can be used by e-patients to ask health questions. In view of this, many e-patients use Twitter to share information about themselves and a few have posted comments to find out about medical matters and share updates about themselves or others (Fox, 2009). However, there are no clear statistics on whether this use of the social network is useful for health services. It appears that the electronic social network is the most popular means by which people can obtain information, knowledge, good relationships, education, and healthcare information, as can be seen from the aforementioned evidence that social networking impacts on society are not problematic. Therefore, it can be seen that media-based relationships and communities have few damaging effects on our society in general.

\section{Conclusions}

In conclusion, the social networks have offered new lives for many people in the world. For that reason, they have become more of a necessity in our daily lives, like water, air and food. Thus, people cannot remove them from their lives. Moreover, people use the social networks to communicate with their family members in different places. They use them to make new relationships with people in different parts of the world. Social networks are used by students and teachers for educational purposes, and by patients and doctors for information on health issues. In the other words, people enjoy using them for many useful activities. Subsequently, it can be stated that social communities may be a wonderful way of forming caring relationships rather than damaging them. This raises the question of why the social network creates problems when it is shown to have many advantages.

\section{REFERENCES}

[1] B. Wellman. C. Haythornthwaite . (1ed).The Internet in Everyday Life. Blackwell Publishers. London. 2002.

[2] C. Irene . The Role of Social Network and Collaborative Culture in Knowledge Sharing and Performance Relations. Online available from http://www.freepatentsonline.com/article/SAM-Advanced Management Journal /296697574 .html .

[3] C. Navarrete. Online Social Networks as Formal Learning Environments: Learner Experience sand Activities. Online available from Error! Hyperlink reference not valid.. 
[4] D. Boyd . N. Ellison. Social Network Sites: Definition, History, and Scholarship. Online available from http://jcmc.indiana.edu/vol13/issue1/boyd.ellison.html .

[5] D. Cooper. Social media could improve your health. Online available from

http://www.abc.net.au/science/articles/2012/07/10/3542020. htm.

[6] D. Phillips . P.Young . Online Public Relations. Kogan Page Limited. London. 2009.

[7] G. Veletsianos. C. Navarrete . Online Social Networks as Formal Learning Environments: Learner Experiences and Activities. Online available from http://www.irrodl.org/index.php/irrodl/article/view/1078/207 7.

[8] J. Gold . Developing Health Promotion Interventions on Social Networking Sites: Recommendations from the FaceSpace Project: Online available from http://www.jmir.org/2012/1/e30/.

[9] J. Horton. Online Public Relations: A Handbook for Practitioners. Quorum books, Westport, Connecticut. London. 2001.

[10] J. Sharp. Social Media in Health Care: Barriers and Future Trends. Online available from http://www.ihealthbeat.org/perspectives/2010/social-media-i $\mathrm{n}$-health-care-barriers-and-future-trends.aspx\#ixzz2DHcmfv $\mathrm{Yb}$.

[11] M. Bakardjieva. Internet society : the internet in everyday life. Sage publications. London.2005.

[12] M.A. Moreno, L.R.Briner, A. Williams, L. Brockman, L. Walker, D.A. Christakis . A content analysis of displayed alcohol references on a social networking web site. Online available from

http://www.jahonline.org/article/S1054-139X(10)00020-0/ab stract.
[13] R. Brown. Public Relations and the Social Web. Kogan Page Limited. London. 2009.

[14] S. Bumgardner. K. Knestis. Social Networking as a Tool for Student and Teacher available at Learning. Online available from

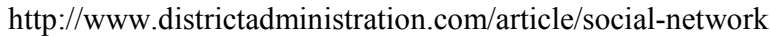
ing-tool-student-and-teacher-learning.

[15] S. Duck. Human Relationships: (4thed), Alden press, Witney. London. 2007.

[16] S. Fox . the Social Life of Health Information. Washington, DC: Pew Internet \& American Life Project Online available from http:// www.pewinternet. org/ /media/Files/Reports/2009/PIP_Health_2009. Pdf.

[17] S. Hrastinski. Aghaee, N. How are campus students using social media to support their studies? An explorative interview study. Online available from http://link.springer.com.libaccess.hud.ac.uk/article/10.1007 \%2Fs10639-011-9169-5.

[18] B.Debatin, J.P. Lovejoy, A.K. Horn., \& B.N.Hughes. Facebook and online privacy: Attitudes, behaviors, and unintended consequences. Journal of Computer - Mediated Communication, 15(1), 83-108. 2009.

[19] M.Borbone. From Doodle to Google: Exacerbating old problems or causing new ones? The relationship between laptop usage and in-class student behavior. 2009.

[20] W.Kondro. Call for arm's-length national research integrity agency. Canadian Medical Association Journal, 176(6), 749-750. 2007.

[21] N.Lin. Social networks and status attainment. Annual review of sociology, 25(1), 467-487. 1999.

[22] D. Fornahl., C. Zellner. and D. Audretsch. The role of labour mobility and informal networks for knowledge transfer. 1st ed. New York, NY: Springer Science+Business Media. 2005. 